\title{
Demonstrating the Anchoring-Adjustment Heuristic and the Power of the Situation
}

\author{
Jannay Morrow \\ Vassar College
}

This article presents a technique used to elucidate the anchoring-adjustment heuristic and to integrate the concept with social psychological principles. After drawing a high or low number out of a hat, students estimated the number of yearly stroke-related deaths that occur in the United States. The interaction between type of anchor and familiarity with the heuristic predicted stroke estimates. Class discussion highlighted the power of situational forces, implications of cognitive biases, and methodological issues. Students' pre- and postdemonstration definitions of the anchoring-adjustment heuristic indicated that the demonstration helped them to understand the concept. Students described the demonstration and discussion as informative and enjoyable.

Many people, even students of psychology, believe they are immune to the influence of the situation. Exposing students to readings and lectures that detail the ways in which situational forces systematically shape behavior does not always prevent students from viewing themselves or their behavior as somehow fundamentally different from what is explained in the material or from proclaiming that they "would never behave like that." As classroom experience and empirical evidence suggest (Myers, 1996; Safer, 1980), even after studying situational influence, self-serving biases, and attributional processes, some students still chastise the susceptibility of Asch's (1955) conformers, condemn the cruelty of Milgram's (1974) "teachers" and Zimbardo's (1973) "guards," and criticize the irrationality of Tversky and Kahneman's (1974) decision makers. By insulating themselves from the behaviors demonstrated in the research, students may find it easier to dismiss or downplay the legitimacy and relevance of research findings.

One way to increase students' awareness of the power of the situation, disarm their skepticism concerning the relevance of research, and enhance their understanding of psychological phenomena is to use demonstrations in which students witness and evaluate how situations influence their own and their peers' behavior. Such participation may help students to recognize the validity of research findings because they can no longer view research participants as less intelligent or more likely to be duped than they are.

This sort of firsthand knowledge may help students to understand the anchoring-adjustment heuristic (AAH). The AAH biases behavior because the anchor-the initial information, behavior, or judgment - creates an inaccurate starting point for subsequent responses or because people make insufficient adjustments from the anchor in light of additional information (Quattrone, 1982; Rottenstreich \& Tversky, 1997). Anchors may have strong effects even when they provide no information concerning the task at hand (Wilson, Houston, Etling, \& Brekke, 1996). For example, Cervone and Peake (1986) tested the effects of an ostensibly random number on self-efficacy and persistence. Before completing a problem-solving task they thought measured mental abilities, participants drew a seemingly random number from a bag. The experimenter actually controlled the draw so that participants drew either a low (4) or high anchor (18). After writing down the anchor, participants predicted the number of problems they could solve. This judgment served as a measure of self-efficacy. Compared to people in the low-anchor condition, those in the high-anchor condition showed higher levels of self-efficacy and more task persistence.

Even though the AAH produces robust effects, students sometimes doubt that irrelevant information can reliably influence people. In addition, many students do not readily see the subtler links between heuristics and social behavior. By showing students that they are not immune to the $\mathrm{AAH}$, this technique aims to diminish their skepticism and advance their conceptual understanding. More specifically, the goals of this technique are to (a) help students understand heuristics and how they work, (b) create links between heuristics and social decision making, (c) touch on the real-world implications of cognitive biases, (d) examine the importance of mindfulness in protecting against unintended social influence, (e) introduce relevant methodological issues, and (f) provide an effective and enjoyable learning experience.

\section{Method}

\section{Participants}

Forty-two undergraduates ( 30 women and 12 men) enrolled in a social psychology course participated in this demonstration. Although participation was not mandatory, all students chose to participate.

\section{Procedure}

Before the demonstration, four lectures and three chapters (Aronson, Ellsworth, Carlsmith, \& Gonzales, 1990; Langer, 1989; Myers, 1996) introduced students to the relevant topics including methodology, social influence, mindlessness, heuristics, and decision making. In addition, I defined the 
AAH and discussed how initial information, including a numeric anchor, may influence subsequent responses.

About one week later, students took a graded quiz that included a multiple-choice question about anchoring and a question that asked them to define the AAH. These questions were part of a regularly scheduled quiz with a variety of multiple-choice and short-answer questions. Students were aware that I might query them about the AAH. I did not provide detailed feedback on their AAH definition. I merely indicated whether it was correct and corrected the multiple-choice answer.

Two sessions later, I began class by introducing a social psychology demonstration. I handed out sheets of paper, and asked students to pass a hat containing the anchors. I asked students to draw a number and write it down on the sheet of paper. I announced that the number was uninformative and meaningless. Approximately half of the students drew a low anchor (340) and half drew a high anchor $(340,627)$. Then, I asked students to write down their estimates of "the number of people in the U.S. who die of stroke each year."

I collected the sheets, and we discussed the purpose of the exercise and what the literature suggests about how their estimates should turn out. Most students believed that the anchor did not influence their estimate and the results for the class would not correspond to those found in the literature. We also discussed the features of a "good experiment" and potential methodological flaws in the exercise.

At the next meeting, I presented the results. I told students that I divided them into groups according to their familiarity with the AAH. I explained that familiarity with the AAH may decrease one's susceptibility to it (Wilson et al., 1996) and referred to the work on mindlessness and resisting persuasion to provide a broader conceptual rationale. I used their answers on the multiple-choice question about anchoring to group them, placing those who answered the question correctly in the high familiarity condition and those who answered incorrectly in the low familiarity condition. I considered a correct multiple-choice answer to be an indication of familiarity with the AAH rather than understanding of the concept because, although many students correctly answered the multiple-choice question (57\%), few provided an accurate definition of the concept $(5 \%)$ on the same quiz.

I analyzed the estimates of the number of deaths due to stroke using a 2 (familiarity) $\times 2$ (type of anchor) ANOVA. The main effects for type of anchor and familiarity were significant, $F(1,38)=10.38, p<.003$, and $F(1,38)=15.69$, $p$ $<.0003$, respectively. These main effects were qualified by the interaction between Type of Anchor $\times$ Familiarity, $F(1$, $38)=14.97, p<.0004$. Figure 1 presents the mean estimated number of deaths.

Pairwise comparisons indicated that the low familiarity-high anchor condition was significantly different from the other three conditions, $p<.05$. No other significant differences emerged.

Two weeks later, students rated the effectiveness of the demonstration and discussion, defined the $\mathrm{AAH}$, and generated written examples of the AAH. Because these questions were not part of a quiz, students were not expecting questions about the $\mathrm{AAH}$, and I did not grade their responses.

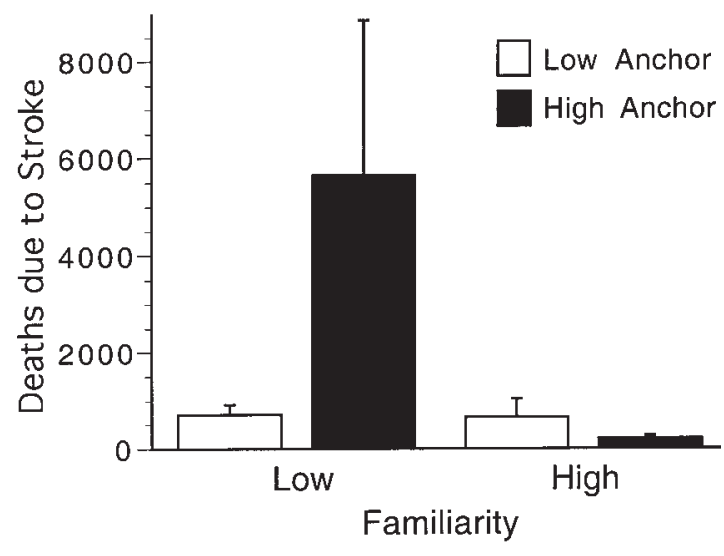

Figure 1. Mean estimated number of deaths due to stroke as a function of type of anchor and familiarity with the anchoring-adjustment concept. Estimates are divided by 1,000.

\section{Evaluation of the Technique}

The definitions of the AAH that the students provided before and after the demonstration and discussion suggest that this technique advanced their understanding of the AAH and of heuristics in general. Before the demonstration approximately $5 \%$ of the students accurately defined the AAH, whereas $90 \%$ did so 2 weeks after the demonstration and discussion. In addition, $75 \%$ of the students provided at least two detailed examples of real-world anchoring effects, which suggests that the discussion may have helped them to think about ways of applying the construct.

These percentages parallel students' perceptions of how much they learned from the demonstration. Overall, students viewed the demonstration and discussion as informative, enjoyable, and interesting (see Table 1).

\section{Discussion}

Our in-class exchanges centered on conceptual connections and methodological issues. We discussed some of the possible mechanisms underlying anchoring-adjustment effects (Rottenstreich \& Tversky, 1997; Wilson et al., 1996) and the effects of the AAH on behaviors such as performance, persistence, and effort (Cervone \& Peake, 1986; Switzer \& Sniezek, 1991).

Our discussion also addressed how the AAH might function in real-world situations, and we considered the ways information other than numbers can serve as an anchor. Next, we moved to how the students' estimates illustrated the ideas that factors outside of the individual can influence thought and behavior and that situational influence can be strong even when external factors seem irrelevant. Students raised examples of first impressions and stereotypes anchoring the judgments of others. In terms of social perception and self-perception, students mentioned some of the ways that initial beliefs about ability, feedback, traits, or performance could anchor future judgments or serve as self-fulfilling prophecies. Other examples concerned advertising, jury decision making, persuasion, and self-consistency.

We turned to whether awareness of a phenomenon could help inoculate one from its effects (Wilson et al., 1996). I pre- 
Table 1. Student Evaluation of the Demonstration and Discussion

\begin{tabular}{lll}
\hline Item & $M$ & $S D$ \\
\hline Helped me to understand the AAH & 6.00 & 0.54 \\
Helped me to understand methodological issues & 5.25 & 1.04 \\
Increased my understanding of how research is & & \\
$\quad$ done & 6.38 & 0.52 \\
Enjoyed the demonstration and discussion & 6.28 & 0.42 \\
Provided an interesting learning experience & 5.87 & 0.84 \\
\hline
\end{tabular}

Note. $\quad N=42$. The questions were counterbalanced. Ratings were converted so that for all questions answers ranged from 1 (strongly disagree) to 7 (strongly agree). $\mathrm{AAH}=$ anchoring-adjustment heuristic.

sented relevant experimental evidence on exposure to the Milgram (Bierbrauer, 1979; Safer, 1980) and Asch paradigms (Lamb \& Alsikafi, 1980; Nemeth \& Chiles, 1988) as well as information on persuasion and mindfulness (Chaiken, Wood, \& Eagly, 1996; Langer, 1989; Langer \& Newman, 1979). We also compared students' estimates with those calculated by the Centers for Disease Control, which reported that the number of yearly stroke-related deaths in the United States is approximately 158,000 (American Heart Association, 2001). We discussed the potential benefits of including estimates of events other than strokes and adding a no-anchor condition. Changes of this sort might help to determine whether a floor effect was operating in the demonstration. Because of the small class size, I chose not to use a no-anchor condition.

One of the liveliest parts of our discussion concerned research design. In addition to discussing experimental control, we touched on ethics, demand characteristics, random assignment, and experimental realism. All of the students had participated in experiments or studies as part of their Introductory Psychology course. Yet, for many of them, this was the first time they immediately saw the meaning of their own responses and were able to discuss the implications of the research, rather than simply being told the hypotheses.

The irrelevance of the anchor, which an instructor may choose to emphasize or deemphasize, afforded a discussion of how decision making can be biased even when information is useless or when people are told to ignore it (e.g., during jury deliberations). Students suggested that seeing the effects of a clearly irrelevant anchor made them less doubtful of the effects of informational anchors, particularly ones that seem relevant, and other types of heuristics. Finally, the use of an irrelevant anchor permitted a natural segue to the limits of the AAH (Chapman \& Johnson, 1994), including a discussion of how anchoring effects are more likely with novel judgments. I have demonstrated this specific point by having students make estimates about novel (e.g., the amount of money spent each year to advertise pet food) and familiar (e.g., the average cost of a textbook) phenomena.

This technique may be adapted for use in introductory psychology classes to illustrate anchoring in forensic decision making, self-efficacy judgments, or the detection of emotion and deception (Chapman \& Bornstein, 1996; Peake \& Cervone, 1989; Williams, 1992; Zuckerman, Koestner, Colella, \& Alton, 1984) or in abnormal psychology classes to point out the potential anchoring effects of cognitive distortions or to elucidate biases in clinical decision making
(Cervone \& Palmer, 1990; Richards \& Wierzbicki, 1990). The effects of the AAH are very reliable, and by altering the decision-making task or by substituting informational anchors for numeric ones, I have found this technique to be highly flexible and useful in many types of classes.

\section{References}

American Heart Association. (2001). 2001 heart and stroke statistical update. Retrieved February 21, 2001, from http:///www.americanheart.org/statistics/stroke.html

Aronson, E., Ellsworth, P. C., Carlsmith, J. M., \& Gonzales, M. H. (1990). Methods of research in social psychology (2nd ed.). New York: McGraw-Hill.

Asch, S. E. (1955, November). Opinions and social pressure. Scientific American, 193, 31-35.

Bierbrauer, G. (1979). Why did he do it? Attribution of obedience and the phenomenon of dispositional bias. European Journal of Social Psychology, 9, 67-84.

Cervone, D., \& Palmer, B. W. (1990). Anchoring biases and the perseverance of self-efficacy beliefs. Cognitive Therapy and Research, 14, 401-416.

Cervone, D., \& Peake, P. K. (1986). Anchoring, efficacy, and action: The influence of judgmental heuristics on self-efficacy judgments and behavior. Journal of Personality and Social Psychology, 50, 492-501.

Chaiken, S., Wood, W., \& Eagly, A. H. (1996). Principles of persuasion. In E. T. Higgins \& A. W. Kruglanski (Eds.), Social psychology: Handbook of basic principles (pp. 702-742). New York: Guilford.

Chapman, G. B., \& Bornstein, B. H. (1996). The more you ask for, the more you get: Anchoring in personal injury verdicts. Applied Cognitive Psychology, 10, 519-540.

Chapman, G. B., \& Johnson, E. J. (1994). The limits of anchoring. Journal of Behavioral Decision Making, 7, 223-242.

Lamb, T. A., \& Alsikafi, M. (1980). Conformity in the Asch experiment: Inner-other directedness and the "defiant subject." Social Behavior and Personality, 8, 13-16.

Langer, E. J. (1989). Mindfulness. Reading, MA: Addison-Wesley.

Langer, E. J., \& Newman, H. M. (1979). The role of mindlessness in a typical social psychological experiment. Personality and Social Psychology Bulletin, 5, 295-298.

Milgram, S. (1974). Obedience to authority: An experimental view. New York: Harper \& Row.

Myers, D. G. (1996). Social psychology (5th ed.). New York: McGraw-Hill.

Nemeth, C., \& Chiles, C. (1988). Modelling courage: The role of dissent in fostering independence. European Journal of Social Psychology, 18, 275-280.

Peake, P. K., \& Cervone, D. (1989). Sequence anchoring and self-efficacy: Primacy effects in the consideration of possibilities. Social Cognition, 7, 31-50.

Quattrone, G. A. (1982). Overattribution and unit formation: When behavior engulfs the person. Journal of Personality and Social Psychology, 42, 593-607.

Richards, M. S., \& Wierzbicki, M. (1990). Anchoring errors in clinical-like judgments. Journal of Clinical Psychology, 46, 358-365.

Rottenstreich, Y., \& Tversky, A. (1997). Unpacking, repacking, and anchoring: Advances in support theory. Psychological Review, 104, 406-415.

Safer, M. A. (1980). Attributing evil to the subject, not the situation: Student reaction to Milgram's film on obedience. Personality and Social Psychology Bulletin, 6, 205-209.

Switzer, F. S., \& Sniezek, J. A. (1991). Judgment processes in motivation: Anchoring and adjustment effects on judgment and behavior. Organizational Behavior and Human Decision Processes, 49, 208-229. 
Tversky, A., \& Kahneman, D. (1974). Judgment under uncertainty: Heuristics and biases. Science, 185, 1124-1131.

Williams, A. D. (1992). Bias and debiasing techniques in forensic psychology. American Journal of Forensic Psychology, 10, 19-26.

Wilson, T. D., Houston, C. E., Etling, K. M., \& Brekke, N. (1996). A new look at anchoring effects: Basic anchoring and its antecedents. Journal of Experimental Psychology: General, 125, 387-402.

Zimbardo, P. G. (1973). On the ethics of intervention in human psychological research: With special reference to the Stanford prison experiment. Cognition, 2, 243-256.

Zuckerman, M., Koestner, R., Colella, M. J., \& Alton, A. O. (1984). Anchoring in the detection of deception and leakage. Journal of Personality and Social Psychology, 47, 301-311.
Notes

1. I thank Susan Nolen-Hoeksema, Philip Zimbardo, Christina Maslach, and my students for their inspiration concerning teaching and research. I developed this demonstration based on ones George Quattrone used in his classes.

2. One of the reviewers suggested the possibility of a floor effect, and I thank the reviewers for all of their helpful comments.

3. Send correspondence to Jannay Morrow, 124 Raymond Avenue, Maildrop 390, Vassar College, Poughkeepsie, NY 12604-0390; e-mail: jamorrow@vassar.edu. 